\title{
22
}

\section{Hagen Settlement Histories: Dispersals and Consolidations}

\author{
Andrew Strathern and Pamela J. Stewart
}

\section{Introduction}

In 1998, we coedited the volume Kuk Heritage: Issues and debates in Papua New Guinea, which brought together the writings of archaeologists and social scientists on the Kuk site project (Strathern and Stewart 1998a). The collection included a chapter by Andrew Moutu of the Papua New Guinea National Museum discussing the archaeological heritage at Kuk (Moutu 1998), reports by Herman Mandui and Nick Araho of the Papua New Guinea National Museum on the archaeological site itself (Araho 1998; Mandui 1998), contributions from Jack Golson and Pamela Swadling (Golson and Swadling 1998) and John Muke (Muke 1998). These contributors, as well as everyone working at Kuk, understand that although archaeology can reveal the deep history of the Kuk site, more recent stories about Kuk are also significant and are an important part of the heritage of Papua New Guinea (Strathern 1972: 37). In this chapter, we present a brief history of some settlement patterns of groups in the Kuk area during the 20th century (Fig. 22.1). ${ }^{1}$

\section{Histories of movement and warfare}

The long-term history of groups of people in the highlands of Papua New Guinea is a history of movements. Either in search of new areas to cultivate or as refugees from warfare, people have constantly been in quest of secure and fertile ecological niches for themselves. In Western Highlands Province, among the Hageners or Melpa speakers, we see another correlate of these patterns of movement: certain named groups became large and powerful, while others dwindled and were made peripheral. In between, there were many groups of medium size who maintained balanced relations of power among themselves. The Kawelka people, who currently inhabit the Kuk area, fall into this third category of medium-sized groups, and their history accordingly is one of making and remaking alliances, struggling for survival and expanding at times when they have been locally successful.

1 For the orthography of Melpa names and places used in this chapter, the spellings we use are consistent with those employed in the corpus of our work since 1965. Other writers follow the spellings used in administrative reports for placenames, such as Buk for our Mbkul, and tribal names, such as Jika for our Ndika. Ndika was the spelling used by the earliest ethnographer of the Central Hagen area, Georg Vicedom. Another spelling is Dika, which does not represent the pre-nasalised character of the initial consonant. As a guide to readers, we prefer to put in the $\mathrm{N}$ to indicate this standard linguistic feature. For extensive discussion of orthographic issues see Stewart, Strathern and Trantow (2011). 


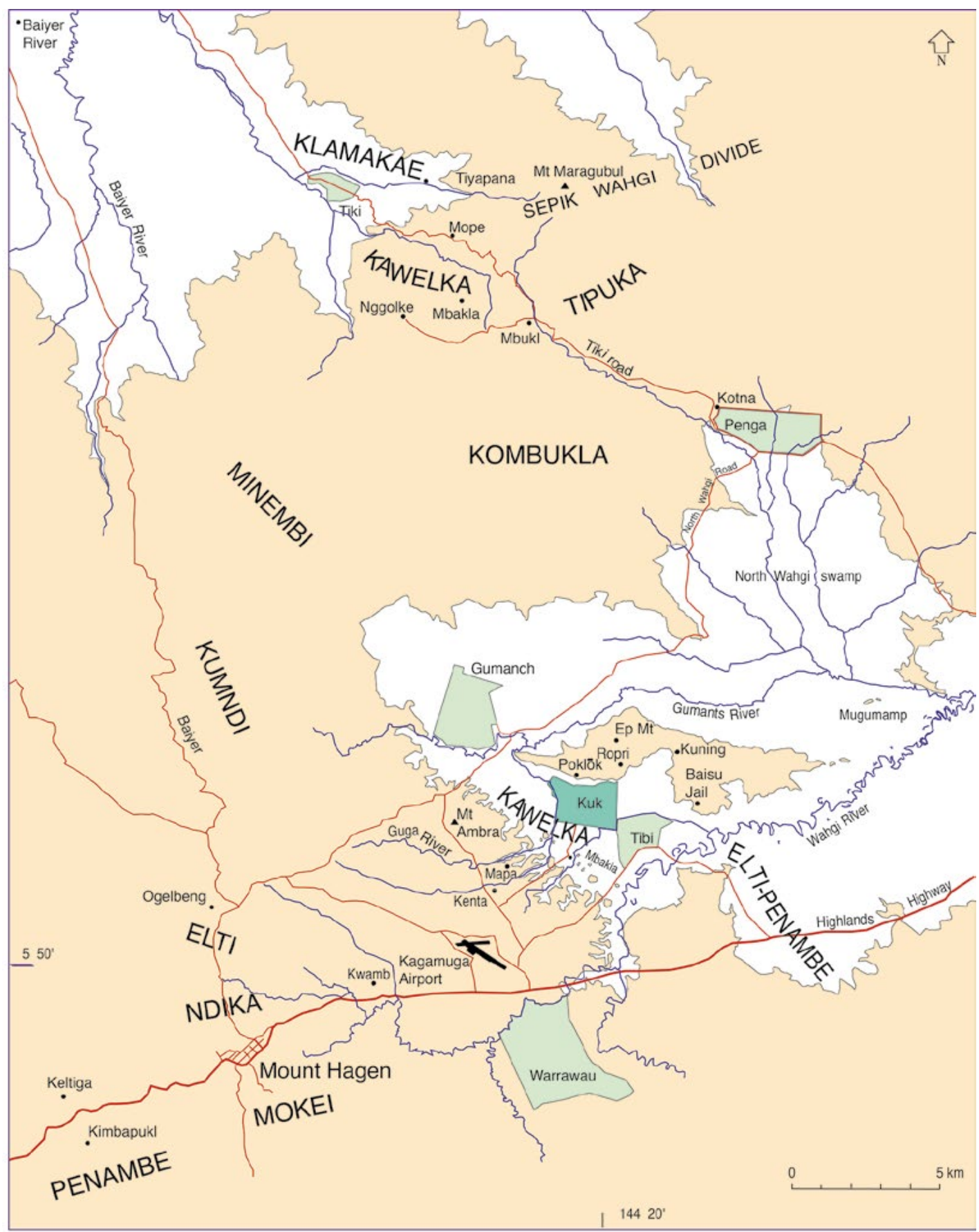

land above $1600 \mathrm{~m}$

plantation

agricultural research station

KAWELKA Melpa speaking group

Figure 22.1 The location of Kuk Station, Melpa-speaking groups and places mentioned in the text (based on Hagen sheet PNG 1:100,000 topographical survey and sketch map by Andrew Strathern and Pamela J. Stewart).

Source: Drawing by Pamela Swadling. 
Population figures gathered in the general Hagen area from the early 1960s give an idea of these differences in size between the named tribal groups at the time. This pattern is close to the precolonial situation at the beginning of the 1930s, when Australian explorers first entered into the highlands from the eastern part of the country. Of a total of 56 such groups in four local government council areas, the overall population according to census return calculations was 58,123 persons, giving an average tribe size of 1037 . At that time the Kawelka, with a population of approximately 860 persons, were positioned slightly below the average size. A more detailed breakdown of the figures indicates that large disparities existed between the sizes of groups. Three very prominent groups-Ndika, Mokei and Kumndi—each had populations of between 5000 and 7000; five groups, including among others the Minembi, enemies of the Kawelka at that time, and the Tipuka, their allies, had populations between 2000 and 5000. A further seven groups, including the Kombukla, paired with the Minembi as their allies at the time, had between 1000 and 2000 persons. The total population for these 15 groups was 41,759, more than two thirds of the overall population total. Below this set of groups in size, a further 11 groups had populations between 500 and 1000, while 26 groups had less than 500 . Together, these 37 groups totalled only 16,364, less than one-third of the overall total and fewer than the combined total of 18,362 for the three largest groups (Strathern 1971: 230-231; Strathern and Stewart 2000a).

These figures make it clear that we are not dealing with groups in demographic balance with one another, but rather with complex effects of warfare on groups, resulting in expansion, decline and migration of groups to peripheral territories over time in response to immediate or imminent pressures. The groups acted to some extent as political units, so it is meaningful to speak of them in these terms. Moreover, these census figures conceal a vital pattern. The largest groups tended to offer protection to smaller ones, while driving away others to different locales. Warfare between the dominant groups, as well as between them and weaker groups around them, contributed to a pattern of groups splitting up and migrating elsewhere as refugees, and this is precisely the pattern we find for the Kawelka. Further, the Kawelka were driven out of their territory at Kuk in the early 20th century by an alliance of groups centred on the Mokei, their former allies. Some sections of the Kawelka were reestablished back into the Kuk area from their northern territory around the place Mbukl with the help of a section of the Ndika people, political rivals of the Mokei at that time (Strathern and Stewart 1998b). Ndika and Mokei are two demographically dominant groups in the Central Hagen area. We can see how the historical position of the Kawelka has been set into the context of their being a small group, which originally migrated into Kuk from elsewhere, living in the interstices of two very powerful groups (namely, the Mokei and Ndika).

\section{Kawelka settlement history}

The Kawelka habitation of Kuk belongs, then, to this overall historical picture. The Kawelka people's own ethnohistory indicates a narrative of travel from Kimbapukl, a putative origin place to the southwest of Kuk, that is paralleled by stories of the northward spread of other neighbouring groups such as the Elti and the Penambe, with whom they were anciently aligned under the overarching name of Pal-Nur, a designation that also included the Mokei people. It also implicates a story of ritual sites where cults such as the Male Spirit cult (Kor Wöp), conducted at the place Kwamb, were held and then abandoned as people moved on (see Stewart and Strathern 2001a: 99-112 on the Wöp). Kawelka settlement at Kuk was accompanied by the naming of several main residence sites throughout the area, which are recorded in ethnohistorical accounts (Strathern, fieldnotes, 1964-65, 1969; Strathern 1972: 36-39). When they began to return to Kuk after colonial efforts at pacification, Kawelka leaders, along with their followers, reestablished 
settlements at these old remembered sites, for example Kenta, Mapa, Kuk, Kuning, Poklök and Ropri (Strathern 1972: 37). They held on to most of them, although conflicts with neighbouring Ndika groups caused them to withdraw from some areas. Such competition over land no doubt had to do with the perceived quality of the land itself and the fact that the members of large groups lived close by to those of smaller ones, setting the stage both for the making of alliances and for the possibility of disputes and power struggles.

During colonial times, before independence in 1975, Australian Government officers were often involved in setting boundary markers between groups, and it appears that at times they had cement posts physically installed between Kawelka lands and those of their neighbours. The placement of these posts was then appealed to by disputants as a permanent record of land rights, although this did not always hold subsequently. Sections of the Kawelka also paid compensation to some of the Ndika for their occupation of gardening ground, in recognition both of the need to settle disputes and to acknowledge the help given them by the Ndika to resettle in the vicinity. After an agricultural station was set up at Kuk in 1969, government officers attempted unsuccessfully to forbid further Kawelka from migrating back there from the Mbukl area.

\section{Reasons for the return to Kuk}

Gorecki (1979) has provided an admirably detailed discussion of Kawelka history and ethnohistory. He poses the question of why the Kawelka came back to Kuk in the 1950s, following 'pacification', noting the decision of Nggoimba, the leader of a section of the Membo clan (Köyambo Elpuklmbo), to leave the general 'Buk' (Mbukl) area and emigrate to a part of 'Kuk' (1979: 99). He goes on: 'Nggoimba’s decision to emigrate must have been important and as suggested by Strathern (1972: 156-158, 247-248), was caused by some areas of Buk having nearly reached their maximum carrying capacity' (Gorecki 1979: 99). In Chapter 23, section 'The prelude', Gorecki refers briefly to this matter, which we examine more closely here.

One of the passages Gorecki quotes reads as follows (Strathern 1972: 156-157):

One account which I have suggests that the moves made by Kawelka men back to the Wahgi were prompted initially by at least a feeling of land-shortage, as well as the aim of finding a better place for pig-keeping. The account was given in 1964 by a big-man Komiti of Membo clan, Kont, who was not one of those that took part in the migration.

'Councillor Nggoimba forbade anyone to plant on his ground at Tiyapana [a settlement area which is just outside the present accepted boundaries of Kawelka occupation]. The river Piling is a boundary between the Klamakae and the Kawelka, but Nggoimba tried to claim Tiyapana. The Klamakae won the court case, so Nggoimba next tried to live at Rokle, Pat, and then at Öm ... but he felt the ground was not good enough. There were too many men and the ground was insufficient for them ... so Nggoimba now decided to go back to his father's place.'

There are several things to notice here. First, the text reports the views of Kont, a Kawelka leader from a different and potentially competitive subclan of the Membo clan, the Oyambo subclan, and Kont dissociated himself from the migration. He and some of his friends hung onto the main Membo ceremonial ground in the heart of Membo land at the place Mope. Second, Kont's account makes it clear that Nggoimba's troubles stemmed from a boundary dispute that was settled in court against him. He and his followers were then forced to look elsewhere, intruding on established settlements. These processes are not the same as an overall objective situation of land shortage stemming from gross population densities of the kind that Gorecki computes. Rather, they are the result of intersubjective and competitive processes occurring in a context where outright fighting between groups was banned and courts now decided cases of conflict. 
The other passage Gorecki refers to runs as follows (Strathern 1972: 247-248):

An interesting part of the history of Kawelka re-colonisation in the Wahgi is Nggoimba's aim of establishing himself as a big-man with supporters in his own territory. It is interesting also, and possibly significant, that many of the men of Membo clan who joined him are non-agnates, either themselves incomers or the sons of incomers—men who may not have felt the same bonds with the Mbukl territory as other Kawelka men appear to feel. Perhaps, also, Membo clan took in too many incomers, thus taxing the capacity of its territory; but this I cannot demonstrate.

Gorecki's statements are cautious, hedged about with words like 'possibly' and 'perhaps'. Nggoimba, too, already had status as a leader in his subclan at Tiyapana. The suggestion is that he had greater freedom to expand his influence further in the new territory and that he gathered around him a set of supporters whose ties with the old territory were not very firm. Gorecki (1979: 99) attributes big-man status to Nggoimba, as well as to the well-known leader of Mandembo clan, Ongka, in 1946. So this would have been Nggoimba's basis for pioneering settlement back at Kuk. However, this does not negate the circumstances pointed out, or claimed, in Kont's narrative.

Gorecki goes on to discuss population densities in the two territories, Buk and Kuk, arguing that densities at Buk were much higher than figures given by Strathern. Again, the passage in question reads (Strathern 1972: 32, 34):

Effective density in the territory of the Kawelka is probably between eighty and a hundred persons per square mile, not very different from the average density for the Central Melpa area (in the early 1960s) of 118.1 persons.

First, it is evident that the figures given for the Kawelka were avowedly approximations, not a definite computation. Second, the figures for the Central Melpa area (which included Kuk) were taken from a council survey/government report. Third, in the same passage it is noted that ' $[\mathrm{t}]$ he Kawelka do not consider themselves to be en bloc short of land' (1972: 34). Fourth, the approximation for the Kawelka overall included Kuk and was not confined to Buk. Fifth and finally, 'Buk' is a simplification of a complex mosaic of situations in different places among different clans and subclans between Mbukl and Tiki.

It is clear from Gorecki's (1979) computations that in November 1958 the Kawelka population living in the Mbukl clan territories ('Buk') was considerably larger than in February 1965 (791 as against 695). This would certainly have meant an overall higher population density at the earlier date (1958), and this in turn supports the notion that land 'shortage' was possibly at work in motivating some of the Kawelka to move back to Kuk. Gorecki further cites a patrol report by Murdock from 1951 in which it was claimed (apparently without details) that the area between the two places Buk and Mala was one of the most heavily populated stretches observed on the patrol (details of the other areas were not given), with a shortage of food around Buk. We may comment here that the area between Buk and Mala includes the large and densely occupied lands of the Tipuka and Welyi tribes in the fertile Möka Valley and only a proportion of the Kawelka land (depending on what is meant by 'Buk', the actual patrol post location on the edges of Kawelka territories or all of the Kawelka locations). The overall point here is that data from Buk and Mala in 1951 do not tell us much about effective population density in a section of the Kawelka in 1960, around the time of the inception of Kawelka initiatives to go back to Kuk and recolonise it. Aims of reclaiming an old territory with fertile land near to the Mount Hagen government centre and with good potential for growing coffee, a new cash crop being gradually introduced by the colonial agricultural officers, were probably to the forefront, in addition to the leadership ambitions of Nggoimba.

We offer these remarks as a set of notes to Gorecki's exposition, in order to make it clear that overall gross population densities need to be recast in more local, experiential and politically motivated terms in accounting for patterns of mobility. 


\section{Settlement places and the land}

One factor that must be remembered is that immediately before the creation of Kuk Tea (later Agricultural) Research Station in 1969, large sections of land in the area near to where the Kawelka and others lived were uninhabited swampy zones. It is precisely in these, of course, that evidence of earlier prehistoric agriculture has been preserved and discovered. The Kawelka themselves knew the extent to which they could or could not profitably venture into the swamps for productive gardening purposes. During the 1970s, older informants were quite clear that the swamp areas were recognised as intractable and unusable and that they could dig their garden ditches (pana ru) only up to the edges of these areas without being able over time to extend their usage or to progressively reclaim land from swamp zones (Strathern, fieldnotes, 1972-78). This evidence indicates that although the Kawelka and others had access to prime land they were also hemmed in, on some sides by hostile neighbours, on others by flooded swamp and in other locales by wooded hillsides. They were able to cultivate the hillsides to some extent-the two settlements Poklök and Ropri mentioned earlier in this chapter are located on the slopes of Ep Ridge at the northern edge of Kawelka territory and were the home settlement areas of Kaepa, the father of a well known Kawelka leader, Ongka-Kaepa (Strathern and Stewart 2000b, 2000c).

When the Kawelka fought with sections of the Mokei, according to Ongka's own 1969 narrative (Strathern 1972: 37):

'Kawelka men were chased into a swamp, where some drowned and others were cut with the axe as they waded in it. Some escaped to the top of Ep hill and others to Poklök [Kaepa's place]'

The Kawelka gathered on Ep hill and there Kaepa held a sacrifice of a large pig brought by the son of a woman of Oyambo clan in the Kawelka group (this clan is now a section of the Membo clan). Acting as a big-man and ritual leader, Kaepa held the tethering rope of the pig and spoke the names of all the settlements they would soon be leaving as refugees, saying (Strathern 1972: 38):

'Now they are driving us out and we must leave you, our places, only a few of us are left and we are going. I am sorry for you, my land, and I am killing this pig for you.'

The intense attachment of the people to their named settlement places and the fusion of personal and collective identity with the land is seen clearly in this narrative. The land as such included also the remains of Kawelka dead buried there and the spirits of these dead (kor kui wamb) might be thought to be attached to these settlements as well. Yet the Kawelka also thought of themselves, as did other Hagen groups, as mobile and migrating. 'Now we are going to Mbakla, our sisters' sons will show us the way', Kaepa said at the conclusion of his speech, referring to their destination near Mbukl at the place Mbakla (Strathern 1972: 38). By the 1960s, this figured as a sacred place of all the Kawelka, a site where the ancient eimb cult was practised for the fertility of the land (on this cult see Strauss and Tischner 1962; Strathern and Stewart 2000b: 40-71; Stewart and Strathern 2001b: 89-90). Mbakla is also the name of a Kawelka settlement place at Kuk.

\section{Landscape, identity and history}

The Kuk site is recognised by Hageners as one that was, and is, exceptionally fertile and therefore desirable. Groups that reside on the land or near it therefore have historically placed a high value on maintaining their claims. Subgroups within groups have also identified with certain areas and tracts of land, and settlement claims are signalled in knowledge of particular names of places. When the Kawelka were driven out from the Kuk territory, as noted above, and had to seek 
refuge to the north, they established placenames in their new territory. The knowledge of these is nowadays encapsulated in speeches that are made for public events. This knowledge of names and of the landscapes that go with the names is an important way of self-conceptualisation that Hageners in general practise. It enables the Kawelka to think of themselves as belonging both to Kuk and to the territories round Mbukl, Mope and Nggolke that they established as immigrants from Kuk. Landscape is thus closely tied to historical notions of identity (see Stewart and Strathern 2003). The placenames at Kuk were in general not transposed onto places in Mbukl, nor have the names at Mbukl been brought back to the Kuk area (an exception is Mbakla). Rather, knowledge of the names specific to each area acts as a focus around which memories and historical consciousness can crystallise. Older speechmakers from the Mbukl area who came in the 1990s to take part in public occasions at Kuk referred to the names of rivers and settlement places at Mbukl, evoking images of past residence, events and persons associated with these names. In January 2000, at the funeral of two men from the area, speeches were interlaced with this imagery of past locale and present locale mixed to form contemporary identity.

The Kawelka today are split between their northern areas around Mbukl and their main central location at Kuk. Warfare in the mid-1980s somewhat weakened the position of those still living near Mbukl, although the Kawelka remained undefeated and even increased parts of their territory in fertile low-lying coffee-growing places near to the Tiki plantation. The story of how they undertook their reverse migration and recolonisation of the Kuk area illustrates the 'patchy' processes whereby colonisation and migration take place generally in the highlands. It also illustrates the important roles of particular leaders who were conscious of their own traditions and eager to recapture the fertile resources they or their parents had left behind more than a generation earlier. The different subgroups, whose narratives cluster around the doings of leaders, tend to maintain distinctive overlapping versions of the history of resettlement, each claiming some precedence in relation to specific tracts of land around the old Kuk Agricultural Station.

\section{Individual narratives: Ongka, Nggoimba, Kundi}

Ongka's narrative from 1969 clearly relates the vital role of his father Kaepa in signalling the Kawelka's continuing historical claim on the land at Kuk, and especially at Ep and Poklök, through his sacrifice of a pig and his naming of settlement places. Kaepa's ritual act was not merely expressive. It declared an ongoing claim to the land at Kuk through the invocation of the names of places and spirits associated with them. Ongka himself, later in his life, returned to Poklök and made his own settlement there (Strathern and Stewart 2000c). Ongka's narrative highlights the significance of the wealthy major leader Koi, after whose death Kaepa decided to make his sacrifice. Another narrative cycle that is well known credits Koi with setting up a stone stele at Kuk (Fig. 22.2) that is now taken as a fiduciary marker of the Kawelka's real claims to the land there (Stewart and Strathern 1998; see also Chapter 23). The narrative records that Koi had this stone brought over to Kuk from Ropri, where it was discovered. In recent historical times, further stones of this kind were in fact found at Ropri and two were brought out and set up at one of the main settlement places of the Membo clan at Kuk, Mbakla. Thus, in two ways Ongka reinforced the point that he was himself tied in with traditions of leadership and political representation among the Kawelka. 


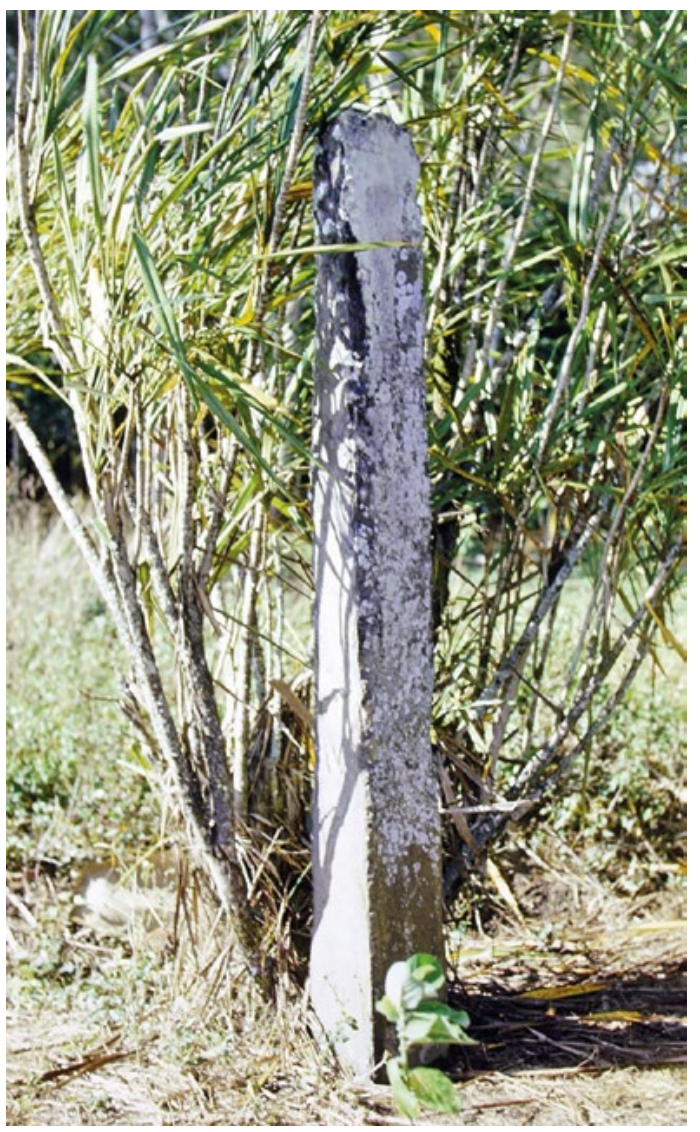

Figure 22.2 The Kuk stone, slab, pillar, stele or obelisk as it has been variously called.

The place of the stone in the story of the Kawelka's departure from Kuk around 1920 and return there from about 1960 is told here, in Chapter 23 and in publications about it that are cited there.

Source: Photograph by Paul Gorecki.

Another set of narratives (see Ketan 1998: 1216, published after Strathern and Stewart 1998a) focuses on the activities of leaders of the Membo clan, including Nggoimba, in pioneering the Kawelka return to Kuk. In 1964, as discussed earlier in this chapter, Kont, a Membo Oyambo subclan leader who stayed at Mope near Mbukl and did not go to Kuk until later, noted that Nggoimba (who was of Köyambo subclan and the grandfather of Ketan) had left his settlement at Tiyapana (north of Mope) and had gone to Kuk after losing a court dispute over land with Klamakae people, so he 'now decided to go back to his father's place. This was his own ground, and now he is firmly established there, and since then many other Membo men have joined him' (Strathern 1972: 157). Notable here is
Kont's conviction that the Membo leader's claims were historically well established at Kuk and that he was returning to his own land, and so went on to draw many supporters around him. As Ketan (1998: 15) notes, Nggoimba was recognised as a leader well before he left for Kuk; but he clearly was able to extend his activities further in a new area along with his followers, including numbers of non-agnatic affiliates of his group (Strathern 1972: 247).

The Kundmbo clan, in turn, maintain a narrative that explains that the overall Kawelka claims on Kuk actually depended on the presence of an old Kundmbo clansman, Kundi, who stayed with some Ndika relatives of his (his mother's people) rather than going to Mbukl, and then opened the way for other Kundmbo men (e.g. Konga and Makla) as well as the Kawelka at large to reoccupy Kuk. According to the narrative, Kundi also played a part in authenticating the overall Kawelka claims to their land when the Australian administration purchased it for a tea research station.

These narrative versions thus make up a patchwork, validating for different parts of the territory the Kawelka's total historical claims to the land at Kuk. The narratives are complementary to one another in the broadest sense, while stressing the singularity of particular claims within the wider framework and emphasising the importance of the claims of particular subgroups. Such divergent narratives are relevant to the land claims of Kawelka groups today in relation to areas designated for World Heritage status.

\section{Conclusion}

Our concern here has been to trace the history of migrations among the Kawelka as illustrative of general patterns of group migrations in the Hagen area. These spatial movements combine ideological elements of fixity and fluidity together. The two elements correspond to historically realised patterns of dispersal and consolidation. We suggest further that these two elements inscribe major characteristic sequences of history in other highlands areas also (Merlan and Rumsey 1991; Stewart and 
Strathern 2001b). A further mechanism whereby populations asserted their territorial claims and their consubstantiality with the ground was the performance of ritual, as Rappaport (1984) has discussed extensively. While periodic exchange festivals and pig kills among the Hageners also had this function, there is also a close parallel with fertility cults, such as the Female Spirit cult, that were performed at generational intervals. A performance of the Kawelka Kurupmbo clan section in 1983-84, sponsored by the family of Ru-Kundil and held near to Raiorong at Kuk, illustrates this point (Strathern, fieldnotes, 1983-84). Groups tend to move over time but also to fix their connections with the ground at a given time through the medium of ritual.

Nowadays, the Christian churches in the area serve this function and are significant loci for the political and spiritual condensation of group solidarity, while the advent of doctrinally different churches, e.g. Catholics and Assemblies of God, presents challenges and precipitates disjunctures among and between groups (for a set of references on these topics and related ones, see the publications listed at www.pitt.edu/ strather). The juxtaposition of cooperation and conflict appears also in the arena of the reoccupation of land in the old Kuk Agricultural Station, including the section designated for World Heritage status.

\section{Appendix 22.1: A Note on Magic Crystals ${ }^{2}$}

\section{Andrew Strathern and Pamela J. Stewart}

In the mid-1960s in Mount Hagen, men quite commonly owned small crystals, which they kept in pouches and could pull out for occasional use in the context of pig-rearing. The crystals were called kng konga ku, 'pig magic stone'. One story that was told was that they were used magically to make the highly valued layer of fat under the skin of a pig copious. The crystal itself was said to embody this property (Strathern, fieldnotes, 1964).

These crystals were quite small and generally corresponded to those that are illustrated in volume 1 of Vicedom and Tischner's three volume study, Die Mbowamb (Vicedom and Tischner 1943-48). This work was published with Herbert Tischner as coauthor, but all of the field materials were collected by Vicedom. On page $126 \mathrm{ff}$. of volume 1, Vicedom gives a discussion of Zaubersteine, magic stones, all of which he says the people find in the earth while digging gardens or nowadays building airstrips. Some of these stones, he notes, are prehistoric artefacts while others are simply natural, such as mountain crystals. These, because of their gestalt (their overall shape), are considered to be beyond the terms of everyday experience. Vicedom (page $126 \mathrm{ff.}$ ) describes the stones as 'glatte, kugelig, abgeschliffene Steine' (smooth, rounded and worn-down stones).

Vicedom (1943-48, vol 1: 128) gives an example of such crystals and notes further that people connect them to the supernatural powers because of their unusual form (Fig. A22.1). In his Figure 35, he reproduces a drawing of one crystal at 80 per cent of its actual size. His drawing measures about $25 \mathrm{~mm}$ at the widest point and about $44 \mathrm{~mm}$ in length. Actual size would thus be about $20 \mathrm{~mm}$ wide and $36 \mathrm{~mm}$ long. Two similarly sized crystals, bound with plant fibre at their tops, appear in Figures 43 and 44. The crystal in Figure 35 was described to Vicedom as 'kung kopena' (pig magic). The sizes of these crystals are similar to ones seen in 1964 by Andrew Strathern (fieldnotes, 1964) when they were still in common use (although there is no definitive evidence that they are abandoned nowadays).

2 The authors were asked to write this appendix because of the interest shown by the workmen at Kuk in the discovery of two quartz crystals during the excavation of a house site (see Chapter 20, section 'Phases 4-6, from 2000 years ago to AD 1900'). 
Vicedom (1943-48, vol 1:128) goes on to give an interesting description of how the crystals were used, as Orakelzauber and perhaps Fernzauber (oracle magic and magic to work at a distance). With regard to their use as oracles (divinatory instruments), Vicedom writes that 'with their help a man can determine the number of piglets that can be expected to be born when a sow farrows. To this end the people lay the crystal in the steam coming up from an earth oven, or else they rub it with pork fat and then wipe off the fluid or fat and then enumerate the resulting iridescent lines that appear in the crystal' (Vicedom 1943-48, vol 1: 128, as translated by the authors). The number of striations, it seems, would be the number of the piglets to be born.

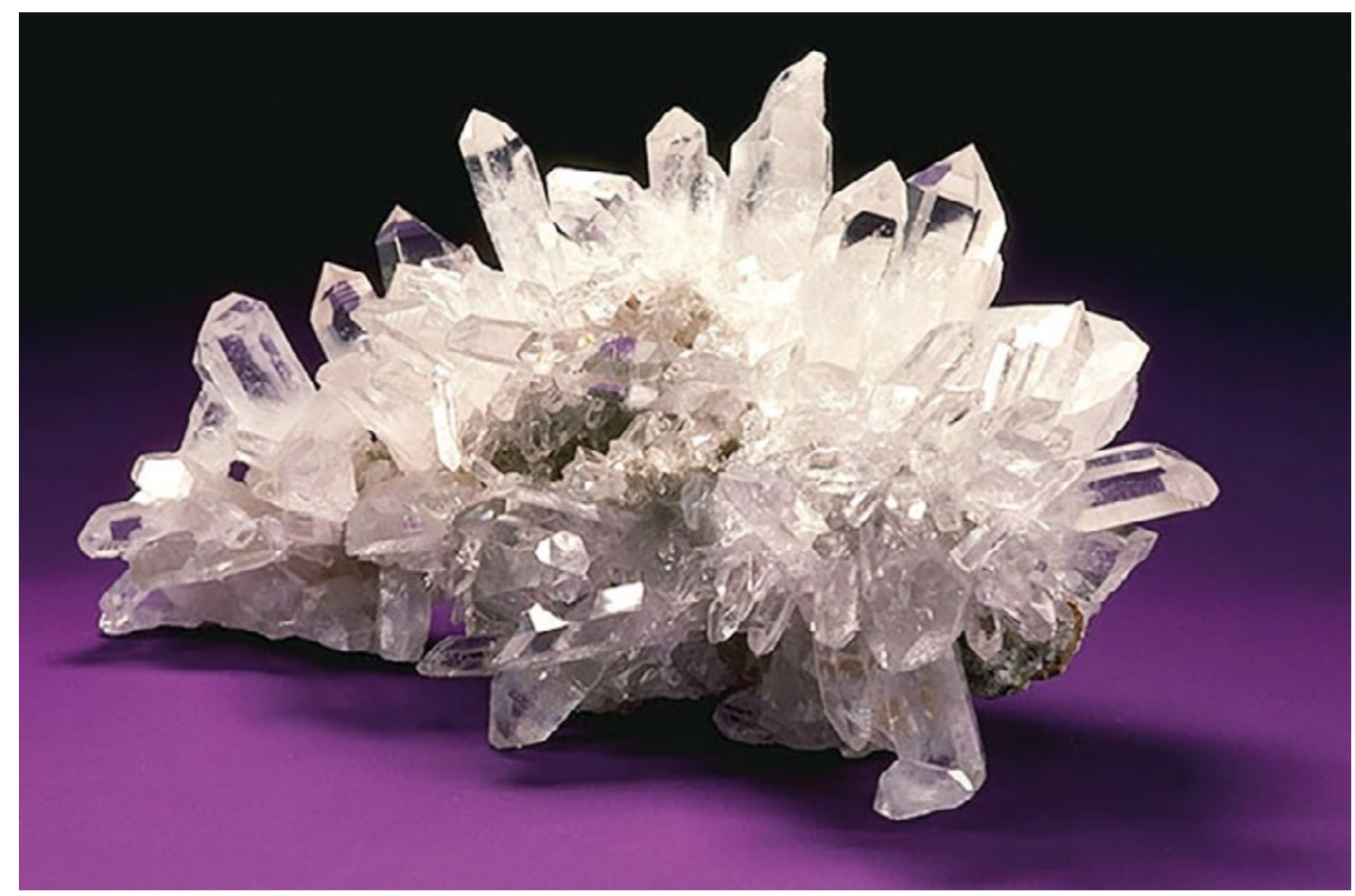

Figure A22.1 The quartz crystals shown here are similar in form to the individual crystals illustrated by Vicedom, as cited in the text.

Source: Photograph by Rob Lavinsky, iRocks.com, commons.wikimedia.org/wiki/File:Quartz-153455.jpg, CC-BY-SA-3.0.

As distance magic stones, 'kopena ketitloa', Vicedom says, 'stones that are simply rounded or eggshaped, smooth and black are in use' (1943-48, vol 1: 131). He goes on to explain that they were employed to harm an enemy at a distance, by pointing or throwing the stone in the direction of the enemy and speaking the magical spell along with the action. Since these distance magic stones are described as 'black', it is not clear whether they were a kind of crystal.

In volume 2 of Die Mbowamb (pp. 331; 368-371), Vicedom discusses magic in general, pointing out the connection of magic with higher powers in the world. Crystals do not appear to have been exclusively possessions of ritual experts, but these latter certainly did carry other magic stones around. Vicedom (1943-48, vol 2: 268) notes that such stones are clearly seen as property and are accordingly passed down from father to son and stay in the family. A ritual expert guards such stones jealously, because they help him to increase his practice. The expert (or medicine man) regards the stones as 'ungeheuer wertvoll' (extraordinarily valuable) (cf. the general discussion of magic stones in highlands Papua New Guinea (PNG) cultures in Stewart and Strathern 1999). 
A comparable use of crystals is found among the Duna people of Hela Province (previously part of Southern Highlands Province) in PNG. Ritual experts who presided over seclusion rituals for boys, intended to help them grow into attractive young men, performed magic for the boys' hair and also gave them small crystals, known as 'ipu rei', to help make the condition of their skin smooth and healthy. Youths would carry these crystals with them on journeys to other settlements, wrapped inside netbags. On such journeys they might be seeking girls with whom they could establish a possibility of courting for marriage at special dance occasions. One senior informant told us that an ipu rei stone might be found inside the stomach of a particular kind of marsupial, and if so it was a gift from the female mountain spirit, the Payame Ima. Another narrative told how a man from Yeru, a locality near to the Strickland River, had seen crystal stones falling down to the earth in volcanic ash emerging from an earthquake and a volcanic eruption. The ash came from Oksapmin west of the Duna area, on the other side of the Strickland River. In general, these crystals were seen as possessions of the Payame Ima, gifted to youths to help them find wives (Stewart and Strathern 2002: 108).

In Duna folk traditions, then, magic crystals belonged to a specific female spirit, the Payame Ima (or her local instantiations, with specific names) and their use was to improve the skin of boys and make them attractive to girls. In Hagen traditions, the stones were carried around by men and were employed in pig magic, including the improvement of the skin quality of pigs. In both cases, the crystals were aids to excellence at different stages of the life cycle. See also Frankel (1986) on sacred underground caves where crystals of the kind discussed here were formed. Such caves were the object of ideas about their numinous power among the Huli. It would be interesting to find out more about the historical diffusion of these esoteric objects from their physical sources in the highlands of PNG. 
This text is taken from Ten Thousand Years of Cultivation at Kuk Swamp in the Highlands of Papua New Guinea, edited by Jack Golson, Tim Denham, Philip Hughes, Pamela Swadling and John Muke, published 2017 by ANU Press, The Australian National University, Canberra, Australia. 